DOI: $10.17805 / z p u .2021 .4 .12$

\title{
Особенности актуальной социально-политической самоидентификации российских граждан
}

\author{
В. К. ЛЕВАШОВ, О. В. ГРЕБНЯК \\ ИНСТИТУТ СОЦИАЛЬНО-ПОЛИТИЧЕСКИХ ИССЛЕДОВАНИЙ ФНИСЦ РАН
}

В статье на основе результатов социологического мониторинга «Как живешь, Россия?» анализируются характер и содержание процессов социальной и политической самоидентификации российских граждан. Результаты исследований демонстрируют тренды адаптивности россиян к сложившейся неустойчивой социальной реальности. Растет уровень гражданского самосознания, что способно дать стимул к дальнейшему развитию гражданского общества. Рост гражданского самосознания происходит на фоне обострения социально-политических противоречий, снижения отдельных показателей по обеспечению государством норм демократической жизни в обществе и гарантий прав и свобод человека и гражданина. Авторы отмечают нарастание внутреннего противоречия между осознанием российскими гражданами своей потенциально значимой роли в становлении гражданского общества и низким уровнем практической возможности реализовать социально-политический потенциал социума в этом направлении.

Ключевые слова: социальная идентификация; гражданское общество; гражданское самосознание; общественные институты; социальная напряженность

\section{ВВЕАЕНИЕ}

2021 год, определенный Правительством РФ как Год науки и технологий, проходит в условиях продолжающейся пандемии коронавируса. Аля России социально-политическая ситуация усложнилась необходимостью проведения парламентских выборов. Оба этих значимых для жизни российского гражданского общества и государства процесса сопровождаются социальными и политическими трансформациями, ростом неравенства в различных сферах, сомнениями и тревогами, вызванными как разнонаправленными дискуссиями на тему вакцинации, так и не менее разнонаправленными обсуждениями характера и результатов прошедших в сентябре 2021 г. выборов. Год науки и технологий проявился, помимо прочего, в форсированном внедрении цифровых технологий, что парадоксально усугубило социальную напряженность и тенденции социального и политического отчуждения в обществе. Внедрение и апробация системы электронного дистанционного голосования в ходе выборов депутатов Государственной Аумы только повысили градус общественных дискуссий о прозрачности и достоверности выборов. Сомнения в безопасности личных данных, тайны голосования, неуверенность в надежности системы и отсутствии подтасовок, законности продления сроков голосования до трех дней и возможности изменения выбора Аля участников дистанционного голосования (напомним, участники дистанционного голосования имели возможность в течение периода голосования вернуться к своему бюллетеню и изменить свой выбор) привели к сомнениям немалой доли граждан в легитимности результатов выборов. Неожиданностью эти процессы не стали. О необходимости правового, регуляторного фундамента, предваряющего технологическую революцию, специалисты, эксперты и ученые говорили уже давно.

Аналитики Центра стратегических разработок сообщали о существовании риска «отставания нормативной и регуляторной базы от изменений, связанных с технологической модернизацией, цифровизацией и платформизацией ключевых от- 
раслей и критических инфраструктур. $<. .>$ Высокая скорость разворачивания новых технологий требует быстрой адаптации законодательной базы, разработки и принятия новых правовых норм для высокотехнологичных продуктов и услуг, которых раньше не было на рынке» (Новая технологическая ..., 2017: 72). Отсутствие правового обоснования цифровой модернизации и привело к мультипликации рисков по мере внедрения информационно-коммуникационных технологий. Существенно важный аспект цифровизации подчеркивает американский исследователь советской науки профессор технологической модернизации без соответствующего изменения общества, в котором эти технологии будут развиваться и функционировать. «Успешная технологическая модернизация зависит от характеристик общества, в котором она преАпринимается, в гораздо большей степени, чем от отдельных технологий, какими бы современными они ни являлись на момент внедрения. Без глубоких социальных реформ, которые сделают российское общество более открытым, восприимчивым, свободным и стимулирующим, отдельные технологии будут иметь лишь частичный эффект с точки зрения модернизации» (Грэхэм, 2014).

\section{ГРАЖААНСКОЕ ОБЩЕСТВО \\ И САМОИАЕНТИФИКАЦИЯ ГРАЖААН}

Гражданское общество в политическом и научном дискурсе подразумевает приоритет демократических норм и ценностей в деятельности органов и представителей госуправления; свободу граждан создавать общественные объединения для открытого выражения и отстаивания своей позиции в любой сфере общественной жизни без прямого государственного влияния. В его основу заложена реализация гарантированных прав и свобод для граждан. Выделяя сущностные черты гражданского общества как социального феномена, следует отметить его как значимую социальную общность, сформированную на принципах политической самоорганизации для реализации - при помощи государства - своих интересов и защиты гражданских прав (Иевашов, 2006).

Социальная идентичность и идентификация дичности имеют множество трактовок в научном сообществе в зависимости от научного направления исследователей и целеполагания (Захарова, 2010; Шакурова, 2012). Авторским целям ближе следующее обобщенное понимание. Самоидентификация личности в качестве субъекта гражданского общества основана на социальной интеграции, позиционировании в социальной среде, с сопутствующим принятием этой среды со всеми ее особенностями, моделями поведения и ценностными ориентирами, принятием гражданских обязанностей и готовностью к проявлению социальной активности.

\section{ХАРАКТЕРИСТИКА \\ И РЕЗУАЬТАТЫ ИССАЕАОВАНИЯ}

Основой для анализа послужили данные 51-го этапа всероссийского социологического мониторинга «Как живешь, Россия?» (Аевашов, Великая, Шушпанова Афанасьев и др., 2021a). Институт социально-политических исследований ФНИСЦ РАН проводит мониторинг с 1992 г., отслеживая динамику постоянно наблюдаемых показателей для изучения социополитической ситуации в стране в контексте становления гражданского общества, построения социального госу- 
дарства и изучения перспектив и возможностей устойчивого развития страны. При проведении ис-следований использована квотно-пропорциональная всероссийская выборка со взаимозависимыми характеристиками генеральной совокупности: пола, возраста, образования, места жительства. В основу территориального размещения выборки легло экономико-географическое районирование страны при соблюдении пропорции численности населения и пропорций между городским и сельским населением. Объем выборочной совокупности составлял на различных этапах 1312-1866 респондентов. Полевой этап исследования проведен в период 28.05.2021 - 18.06.2021 в следующих регионах Российской Федерации: УрФО (Челябинская область, Екатеринбург, Свердловская область), СФО (Новосибирская область), ЮФО (Ростов-на-Аону, Азов, Краснодарский край), СКФО (Ставропольский край), ЦФО (Ярославская область, Москва, Московская обл.), ПФО (Нижегородская область, Татарстан), АФО (Владивосток), СЗФО (СанктПетербург, Аенинградская область).

В число периодически отслеживаемых показателей мониторинга «Как живешь, Россия?» входит комплекс вопросов, уточняющих самоопределение своего места в обществе. По блоку категорий определяется самоопределение собственного места в обществе в целом. Респондентам был задан вопрос: «Как вы считаете, какое место в нашем обществе вы занимаете по своему образованию, профессии, другим сторонам жизни?»- с возможностью отметить свой выбор по десятибалльной шкале. Средний показатель по большинству параметров оказался выше среднего и продемонстрировал рост в сравнении с данными прошлых лет по каждой строке (см. таблицу, с. 150). Средний балл по параметрам образования, профессии, квалификации и выполняемой работе (учебе) преодолел средний показатель в 6 баллов. Показатель «место в обществе по качеству жизни» составил 5,3 балла. По сравнению с предыдущим замером в 2019 г. рост среднего балла составил 0,8. 3десь важно отметить, что это первый серьезный рост показателя с 2015 г.

В наименьшей степени изменения затронули идентификацию по размеру денежного дохода и по участию в политической жизни страны (рост среднего показателя по 0,4). Самооценки по участию в политической жизни страны оказались по результатам исследования самыми низкими, не приближаясь к средним значениям, и составили 3,0 балла. В целом по исследованию граждане проявляют рост гражданской инициативы, гражданского самосознания, но результат ее столкновения с возможностями реализации своего гражданского потенциала в политической жизни страны приводит к низкому итоговому результату.

Рост индикаторов социальной идентификации говорит об адаптации граждан к существующей реальности, несмотря на явную социальную и политическую нестабильность последнего периода. Эта нестабильность во многом вызвана затянувшимся ковид-кризисом, экономическими проблемами предприятий, медицинскими трудностями, целым комплексом сложностей, вызванных стремительным наращиванием ввода цифровых технологий в жизнь общества: сюда можно отнести сопутствующий рост неравенства, опасения за безопасность личных данных и уровень вмешательства в жизнь каждого гражданина и пр.

Растущий, невзирая на сложности, уровень самоидентификации - самооценки - напрямую связан с ростом гражданской ответственности и самосознания российских граждан. Повышаются внутренние критерии оценки окружающей действительности и готовность участвовать в ее трансформации. Социологическое 


\section{СОЦИААЬНАЯ САМОИАЕНТИФИКАЦИЯ РЕСПОНАЕНТОВ 1 \\ (РОССИЙСКАЯ ФЕАЕРАЦИЯ, БАА Ы ПО АЕСЯТИБАА ЬНОЙ ШКААЕ) \\ SOCIAL SELF-IDENTIFICATION OF RESPONDENTS \\ (RUSSIAN FEDERATION, POINTS ON A TEN-POINT SCALE)}

\begin{tabular}{|c|c|c|c|c|c|c|c|c|c|c|c|c|}
\hline Индикатор & §ิ & $\begin{array}{l}\overline{1} \\
\stackrel{2}{2}\end{array}$ & $\stackrel{-}{\grave{2}}$ & $\begin{array}{l}\beth \\
\infty \\
\stackrel{2}{2}\end{array}$ & $\begin{array}{l}5 \\
\infty \\
\infty \\
\infty\end{array}$ & $\begin{array}{l}5 \\
\stackrel{2}{2} \\
\stackrel{2}{2}\end{array}$ & $\begin{array}{l}\stackrel{\Delta}{\Delta} \\
\stackrel{2}{D}\end{array}$ & 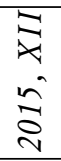 & 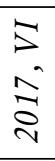 & $\begin{array}{l}p \\
\infty \\
\stackrel{2}{v}\end{array}$ & $\begin{array}{l}\bar{i} \\
2 \\
\vdots \\
2\end{array}$ & 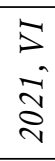 \\
\hline $\begin{array}{c}\text { Место в обществе } \\
\text { по образованию }\end{array}$ & 5,4 & 5,7 & 5,8 & 5,7 & 5,3 & 5,7 & 5,9 & 5,5 & 5,8 & 5,7 & 5,5 & 6,5 \\
\hline $\begin{array}{c}\text { Место в обществе } \\
\text { по профессии }\end{array}$ & 5,5 & 5,4 & 5,7 & 5,6 & 5,6 & 5,6 & 5,6 & 5,4 & 5,8 & 5,6 & 5,5 & 6,3 \\
\hline $\begin{array}{l}\text { Место в обществе } \\
\text { по квалификации }\end{array}$ & 5,9 & 5,8 & 6,0 & 5,9 & 5,6 & 5,9 & 5,6 & 5,6 & 5,9 & 5,8 & 5,7 & 6,3 \\
\hline $\begin{array}{l}\text { Место в обществе } \\
\text { по выполняемой работе, } \\
\text { учебе }\end{array}$ & 5,3 & 5,5 & 5,7 & 5,8 & 5,7 & 5,9 & 5,8 & 5,6 & 5,7 & 5,6 & 5,6 & 6,2 \\
\hline $\begin{array}{l}\text { Место в обществе } \\
\text { по размеру денежного } \\
\text { дохода }\end{array}$ & 3,4 & 3,5 & 3,8 & 4,0 & 3,9 & 4,1 & 4,5 & 4,1 & 4,2 & 4,3 & 4,1 & 4,5 \\
\hline $\begin{array}{l}\text { Место в обществе } \\
\text { по качеству жизни }\end{array}$ & 3,7 & 4,0 & 4,4 & 4,3 & 4,2 & 4,6 & 5 & 4,5 & 4,5 & 4,6 & 4,5 & 5,3 \\
\hline $\begin{array}{l}\text { Место в обществе } \\
\text { по участию в политической } \\
\text { жизни страны }\end{array}$ & 2,5 & 2,3 & 2,8 & 3,1 & 2,8 & 3,0 & 3,3 & 2,7 & 2,7 & 2,8 & 2,6 & 3,0 \\
\hline Место в обществе в целом & 4,5 & 4,6 & 4,9 & 4,9 & 4,7 & 5,0 & 5,1 & 4,7 & 4,9 & 4,9 & 4,8 & 5,4 \\
\hline
\end{tabular}

измерение показало снижение процента затруднившихся ответить по подавляющему большинству вопросов участвовавших в опросе.

\section{ГРАЖААНЕ О ПОАИТИЧЕСКОЙ СИСТЕМЕ \\ И НОРМАХ АЕМОКРАТИЧЕСКОЙ ЖИЗНИ ОБЩЕСТВА}

Новое распределение оценок подчеркивает новый критический подход. Обсуждая отношение к политической системе общества, удовлетворенность ею выразили лишь 9\% (в 2020 г. - 33\%). Продолжительность мониторинга позволяет отметить, что ниже границы в 10\% этот показатель опускался в 2009 г. В свою очередь, число сторонников изменений политической системы выросло. В числе сторонников кардинальных перемен (вариант «политическую систему необходимо изменить радикальным образом») оказалось 34\% респондентов (в 2020 г. - 18\%); реформаторы (вариант «недостатков много, но их можно устранить реформами») составили $47 \%$ (в 2020 г. - 34\%). Количество затруднившихся ответить по этому вопросу респондентов снизилось с 15 до $10 \%$ (рис. 1).

Анализ динамики индикаторов показывает рост недоверия к общественным структурам и институтам власти (ко всем без исключения), что влечет за собой недоверие и к инициативам властных и общественных институтов. Это показал проведенный авторами анализ комментариев к сообщениям в СМИ, дискуссий на форумах, в социальных сетях. При обсуждении сохраняющихся в стране ограничительных мер (масочный режим, запрет массовых мероприятий и пр.); изменений 


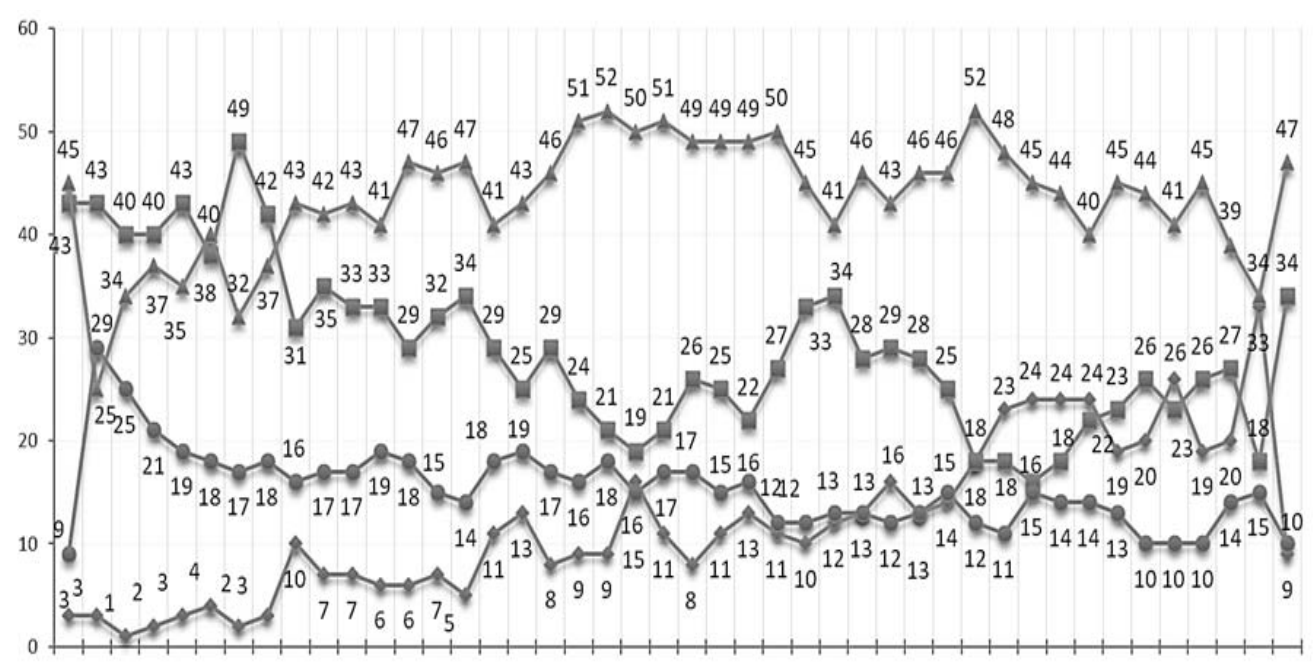

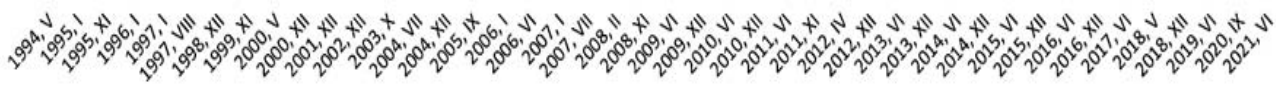
$\leadsto$ Меня полностью устраивает политическая система нашего общества
--Поволитическую систему необходимо изменить радикальным образом
-Много недостатков, но их можно устранить реформами
- -Затруднились ответить

Рис. 1. Отношение респондентов к политической системе общества (Российская Федерачия, \% от числа опрошенньх)

Picture 1. Respondents' attitudes towards the political system of society

(Russian Federation, percentage of the number of respondents)

статистики по коронавирусу; ввода QR-кодов; сопровождаемых призами и бонусами призывов к массовой вакцинации, а позже и к электронному голосованию на выборах в Государственную Ауму, граждане в первую очередь ищут интерес, выгоду для властных, провластных и зависимых от властей общественных структур.

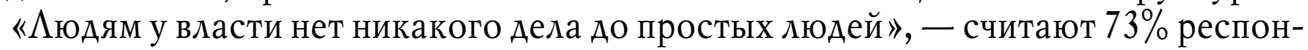
дентов. «Большинство из нас не могут повлиять на политические процессы в стра-

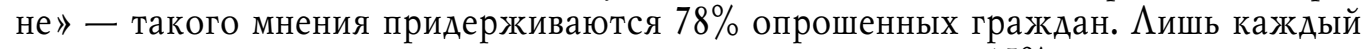
шестой видит в государстве защитника своих интересов: 15\% отметили вариант «власти заботятся о жизни простых людей». Граждане стремятся повысить свой социальный статус, но не могут прорваться к участию в политических процессах. Не видят результата своих усилий. Более того, считают, что их лишают не только возможности участия в становлении действующего гражданского общества, но и законных гражданских прав. Происходит постепенное нарастание социального отчуждения, все больше граждан начинают испытывать недоверие к властям, неудовлетворенность ее действиями (или бездействием). Падает доверие к фундаментальным институтам общества и государства. Так, оценивая степень обеспечения государством основных норм жизни демократического общества в стране, респонденты отмечают, что серьезно «просели» свобода слова (-8 п. п.), терпимость к чужому мнению (-3 п. п.), свобода политического выбора (-11 п. п) (рис. 2, с. 152). 


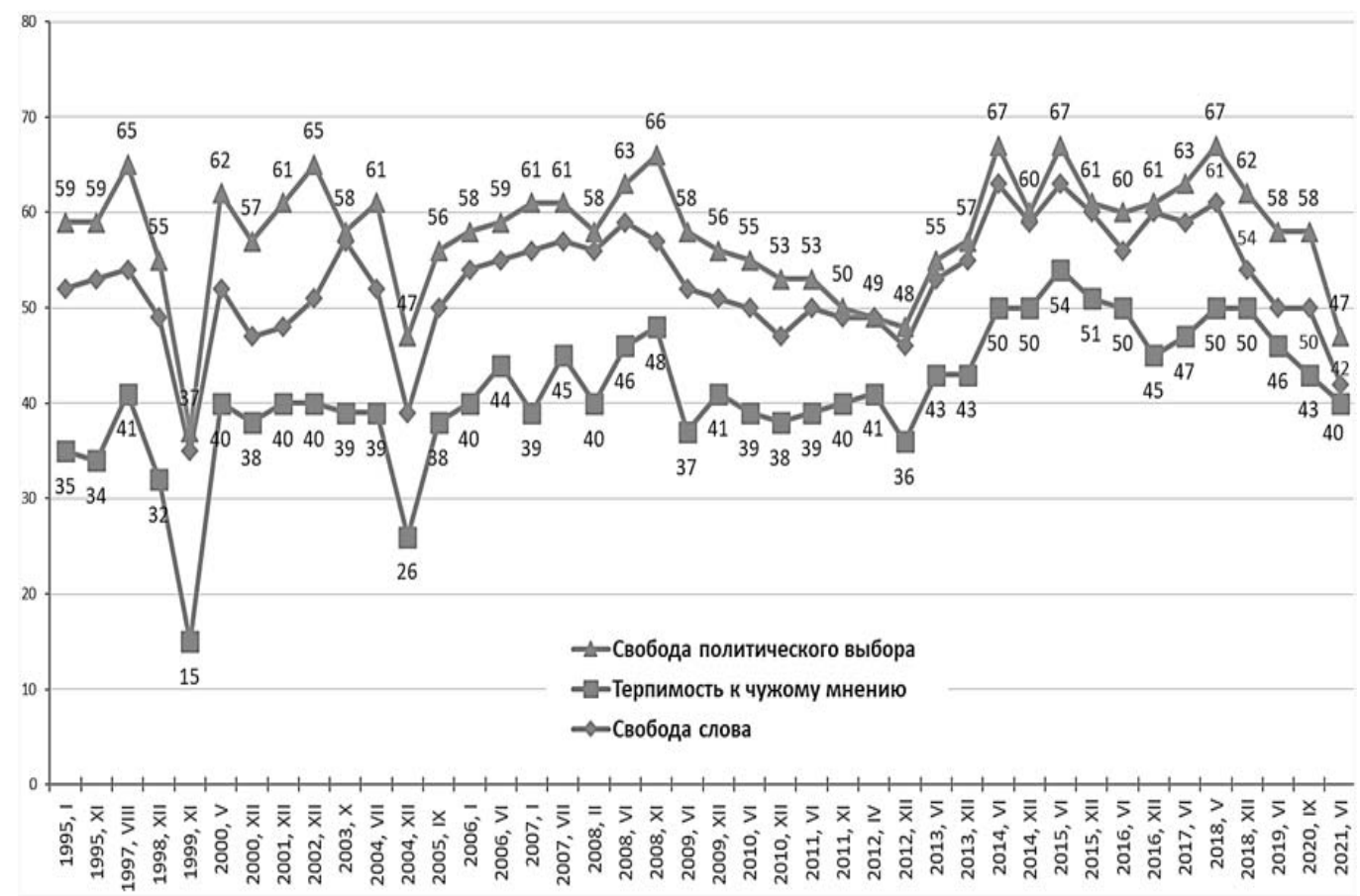

Рис. 2. Мнение респондентов об обеспечении государством основных норм жизни демократического общества в нашей стране, вариант ответа "обеспечиваются" (Российская Федерачия, \% от числа опрошенных)

Picture 2. Respondents' opinion about the provision by the state of basic standards of democratic society in our country, answer option "are provided"

(Russian Federation, percentage of the number of respondents)

Развитие демократических основ напрямую связано с формированием устойчивого гражданского общества и социального государства. Отметим, что годом ранее, в жестких условиях коронавирусной пандемии властям удалось по отдельным индикаторам улучшить оценку демократических основ развития российского общества: «социальные гарантии» и «равенство всех граждан перед законом». За весь период мониторинговых социологических замеров в сентябре 2020 г. данные показатели достигли наибольших значений. По другим индикаторам наблюдалось снижение значений (Иевашов, Великая, Шушпанова, Афанасьев и др., 2021b).

Возвращаясь к актуальному исследованию, отметим, что согласно оценке выполнения государством обязанностей по обеспечению гарантий прав и свобод человека и гражданина, на 22(!) п. п. выросло число респондентов, считающих, что их право на свободу мысли и слова не гарантируется государством. «Не выполняется» отметили к этому пункту $27 \%$ в 2020 г. и $49 \%$ в 2021 г. А ведь, по сути, права человека и автономия граждан служат нормативно-ценностным фундаментом гражданского общества.

В целом оценка общего уровня развития гражданского общества (среднее от показателей восьми оценочных индикаторов) составляет по результатам послед- 
него исследования 5,1 балла. Значение колеблется в последние годы в пределах 0,1 балла, что говорит о стагнации, отсутствии положительного развития.

\section{ЗАКАЮЧЕНИЕ}

Подводя итоги, отметим выявленные в обществе тенденции. Граждане демонстрируют растущее недоверие к общественным институтам, к институтам власти, акцентируют внимание на безразличии к реальным потребностям граждан, выражают недовольство существующей политической системой общества. При этом снижается инертность, безразличие к происходящим в социуме процессам. По всем направлениям социальной самоидентификации граждан наблюдается рост - несмотря на нестабильность социальных процессов и растущий уровень тревожности в обществе. При этом наименьшее стремление к росту $(0,4$ п. п.) демонстрирует индикатор самоидентификации «мое место в обществе по участию в политической жизни страны».

Таким образом, мы наблюдаем рост гражданского самосознания у россиян, стремление к анализу и оценке социально-политической ситуации, готовность участвовать в жизни социума, укреплять и продвигать структуры гражданского общества. И в то же время недоверие к институтам власти, дистанцирование, отчуждение граждан от власти и ее механизмов затрудняют реализацию этого потенциала, что неизбежно приводит к наращиванию социальной напряженности в обществе. От дальнейших действий властей, в том числе новых парламентариев, будут зависеть возможности разрешения сложившегося противоречия и перспективы становления гражданского общества.

\section{ПРИМЕЧАНИЕ}

1 Распределение ответов на вопрос: «Как вы считаете, какое место в нашем обществе вы занимаете по своему образованию, профессии, другим сторонам жизни? Отметьте по шкале свое место, исходя из того, что 10 - это высшая ступень, а 1 - низшая ступень в обществе».

\section{СПИСОК АИТЕРАТУРЫ}

Грэхэм, А. (2014) Сможет ли Россия конкурировать? История инноваций в царской, советской и современной России / пер. с англ. Ю. Константиновой. Москва : Манн, Иванов и Фербер. 166 с.

Захарова, О. В. (2010) Социальная идентификация и социальная идентичность в изменяющемся обществе : учеб.-метод. пособие. Иркутск : Изд-во Иркутского государственного университета. 95 с.

Аевашов, В. К., Великая, Н. М., Шушпанова, И. С., Афанасьев, В. А. и др. (2021а) Как живешь, Россия? Экспресс-информация. 51 этап социологического мониторинга, июнь 2021 года / отв. ред. В. К. Иевашов. М. : ФНИСЦ РАН. 68 с.

Аевашов, В. К., Великая, Н. М., Шушпанова, И. С., Афанасьев, В. А. и др. (2021b) Социальное государство и гражданское общество в условиях реализации национальных проектов. М. : ФНИСЦ РАН. 128 с. DOI 10.19181/monogr.978-5-896-973522.2021

Аевашов, В. К. (2006) Состоялось ли гражданское общество в России? // Мониторинг общественного мнения: экономические и социальные перемены. № 2 (78). С. 54-62.

Новая технологическая революция: вызовы и возможности для России : экспертно-аналитический доклад / науч. рук. В. Н. Княгинина. 2017. М. : ЦСР. 136 с.

Шакурова, А. В. (2012) История становления понятия «социальная идентичность» в зарубежной социологии и социальной психологии // Современные исследования социальных проблем (электронный научный журнал). № 2. URL: https://cyberleninka.ru/article/n/ 
istoriya-stanovleniya-ponyatiya-sotsialnaya-identichnost-v-zarubezhnoy-sotsiologii-i-sotsialnoy-psihologii (дата обращения: 12.07.2021).

Аата поступления: 05.09.2021 2.

\author{
PECULIARITIES OF ACUTE SOCIAL \\ AND POLITICAL SELF-IDENTITY OF RUSSIAN PEOPLE \\ V. K. LeVAShov, O. V. GREBNyAK \\ Institute of SoCIO-Political RESEARCH - BRANCH of THE FEDERAL CENTER \\ of THEORETICAL AND APPLIED SOCIOLOGY OF THE RUSSIAN ACADEMY OF SCIENCES
}

The paper is based on the results the sociological monitoring "How Are You Doing, Russia?" and analyses the nature and content of the processes of social and political self-identification of Russian people. The results of studies demonstrate the trends in Russian people's adaptability to the existing unstable social reality. The level of civil consciousness is also growing, which could give impetus to the further development of civil society. The growth of civil consciousness is happening against a background of aggravating socio-political contradictions, reduction of certain indicators of the state ensuring the norms of democratic life in society, and guarantees of human and civil rights and freedoms. The authors note the growing internal contradiction between Russian citizens' awareness of their potentially significant role in the formation of a civil society and the practical inability to realize their socio-political potential in this direction.

Keywords: social identification; civil society; civic consciousness; public institutions; social tension

\title{
REFERENCES
}

Grjehjem, L. (2014) Smozhet li Rossija konkurirovat'? Istorija innovacij v carskoj, sovetskoj $i$ sovremennoj Rossii / transl. from English by Yu. Konstantinova. Moscow, Mann, Ivanov \& Ferber. 166 p. (In Russ.).

Zaharova, O. V. (2010) Social'naja identifikacija $i$ social'naja identichnost' $v$ izmenjajushbemsja obshbestve. Irkutsk, Irkutsk State University. 95 p. (In Russ.).

Levashov, V. K., Velikaja, N. M., Shushpanova I. S., Afanas'ev, V. A. et al. (2021a) Kak zbivesh', Rossija? Jekspress-informacija. 51 jetap sociologicheskogo monitoringa, ijun' 2021 goda/ ed. by V. K. Levashov. Moscow, Federal Research Sociological Center of the Russian Academy of Sciences. 68 p. (In Russ.).

Levashov, V. K., Velikaja, N. M., Shushpanova, I. S., Afanas'ev, V. A. et al. (2021b) Social'noe gosudarstvo $i$ grazbdanskoe obshbestvo $v$ uslovijab realizacii nacional' nyb proektov. Moscow, Moscow, Federal Research Sociological Center of the Russian Academy of Sciences. 128 p. DOI 10.19181/monogr.978-5-896-973522.2021. (In Russ.).

Levashov, V. K. (2006) Sostojalos' li grazhdanskoe obshhestvo v Rossii? Monitoring obshbestvennogo mnenija: jekonomicheskie $i$ social'nye peremeny. no. 2 (78), pp. 54-62. (In Russ.).

Novaja tebnologicheskaja revoljucija: vyzovy $i$ vozmozhnosti dlja Rossii: jekspertno-analiticheskij doklad (2017) / acad. advisor V. N. Knjaginina. Moscow, Center for Strategic Research. 136 p. (In Russ.).

Shakurova, A. V. (2012) Istorija stanovlenija ponjatija «social'naja identichnost'» v zarubezhnoj sociologii i social'noj psihologii. Sovremennye issledovanija social' nyb problem (jelektronnyj nauchnyj zhurnal), no 2 [online] Available at: https://cyberleninka.ru/article/n/istoriyastanovleniya-ponyatiya-sotsialnaya-identichnost-v-zarubezhnoy-sotsiologii-i-sotsialnoy-psihologii (accessed: 12.07.2021). (In Russ.).

Submission date: 05.09.2021.

Аевашов Виктор Константинович - доктор социологических наук, директор Института социально-политических исследований ФНИСЦ РАН, руководитель Центра социальных 
и социально-политических исследований ИСПИ ФНИСЦ РАН. Адрес: 19333, Россия, г. Москва, ул. Фотиевой, д. 6, стр. 1. Тел.: +7 (499) 530-27-32. Эл. адрес: levachov@mail.ru

Гребняк Оксана Валерьевна - младший научный сотрудник Центра социальных и социально-политических исследований ИСПИ ФНИСЦ РАН. Адрес: 19333, Россия, г. Москва, ул. Фотиевой, д. 6, стр. 1. Тел.: +7 (499) 530-27-32. Эл. адрес: oksananov@yandex.ru

Levashov Viktor Konstantinovich, Doctor of Sociology, Director, Institute of Socio-Political Research - Branch of the Federal Center of Theoretical and Applied Sociology of the Russian Academy of Sciences, Head, Center for Social and Socio-Political Research, ISPR FCTAS RAS. Postal address: 6, Fotievoi St., Bldg. 1, Moscow, Russian Federation, 119333. Tel.: +7 (499) 530-27-32. E-mail: levachov@mail.ru

Grebnyak Oksana Valeryevna, Junior Researcher, Center for Social and Socio-Political Research ISPR FCTAS RAS. Postal address: 6, Fotievoi St., Bldg. 1, Moscow, Russian Federation, 119333. Tel.: +7 (499) 530-27-32.E-mail: oksananov@yandex.ru 